
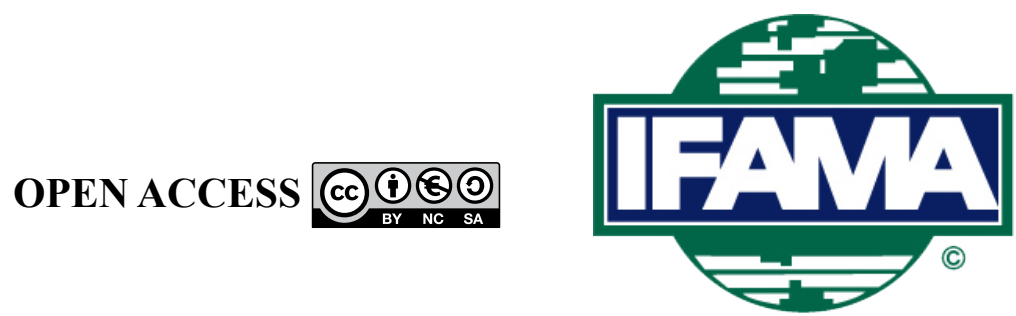

International Food and Agribusiness Management Review

Volume 25, Issue 2, 2022; DOI: 10.22434/IFAMR2021.0048

Received: 17 April 2021 / Accepted: 17 October 2021

\title{
The interaction relationships among agricultural certification labels or brands: evidence from Chinese consumer preference for fresh produce RESEARCH ARTICLE
}

\author{
Yiqin Wang ${ }^{\mathrm{a}}$, Jingbin Wang ${ }^{\mathrm{b}}$, Dan Han ${ }^{\mathrm{c}}$, Shanshan Lv ${ }^{\mathrm{b}}$, Mo Chen ${ }^{\mathrm{d}}$ and Shijiu Yin ${ }^{\oplus d}$ \\ ${ }^{a}$ Doctoral Student, College of Economics \& Management, South China \\ Agricultural University, Guangzhou 510642, China P.R. \\ ${ }^{b}$ MSc, ${ }^{d}$ Professor, School of Economics, Qufu Normal University, Rizhao 276826, China P.R. \\ ${ }^{c}$ Associate Professor, Business school, Jinan University, Jinan 250022, China P.R.
}

\begin{abstract}
China uses a multilevel agricultural certification system; however, its implications are not well understood. In this study, we used tomatoes as an example in a series of Becker-DeGroot-Marschak auction experiments to determine consumers' willingness to pay (WTP) toward three safety certification labels and two kinds of brands. Then, based on the auction experiment results, we designed a menu-based choice experiment to assess the interaction relationships between the safety certification labels and brands. The results showed that consumers were generally willing to pay a premium for tomatoes with safety-certified labels (especially for organic labels) and brands (especially for the enterprise brand). Providing consumers with additional information regarding the certification remarkably improved their WTP for tomatoes with organic and green labels. The menu-based choice experiment suggested that the organic and green labels were found to be substitutes. In addition, organic and green labels could not substitute the enterprise brand, whereas the converse of this relationship was true. Finally, a mutual substitution relationship was observed between hazard-free label and enterprise brand. Our research enables producers to consider the interaction between certification strategies and brand strategies. Therefore, marketers and policymakers should take steps to promote and expand consumers' knowledge on certification, as it could benefit the development of certified food.
\end{abstract}

Keywords: consumer preference, interaction relationship, agricultural certification label, agricultural brand, menu-based choice experiment

JEL code: Q13 Q18

\footnotetext{
${ }^{\oplus}$ Corresponding author: ysjtougao@163.com; yinshijiu@qfnu.edu.cn
} 


\section{Introduction}

To improve the agricultural ecological environment and level of food safety, China has implemented a multilevel certification system since the end of the last century (Liu et al., 2013). This system comprises three labels corresponding to three separate levels of safety and environment requirements: organic, green, and hazard-free (Yin et al., 2017). In China, the organic label represents the highest level of requirement for food safety and the environment in production by dictating that no synthetic fertilizer, pesticide, or genetic modification technique is to be used during production. The green label suggests that, during production, only limited and approved amounts of synthetic fertilizers and pesticides can be used. The hazard-free label is defined similarly to the green label, but with less stringent standards. This label mainly aims to certify foods that are safe for human consumption without prioritizing environmental sustainability. Since the beginning of the $21^{\text {st }}$ century, the Chinese certified food market has been developing rapidly. Chinese consumers have become relatively familiar with the hazard-free label, but do not have a clear understanding of the organic/ green label (Liu et al., 2013). Some consumers cannot even distinguish between organic and green foods (Chen et al., 2019).

Chinese consumers' perception of producer food safety reputation, especially that of small-scale producers, is generally low (Liao et al., 2018; Yin et al., 2018). Although food safety attributes may not be easily accessible in most cases, for consumers, the brand can be considered a 'search attribute' when making food choices (Ahmad and Anders, 2012). Branding decreases consumers' search cost for food safety-related information and reputable brands can claim a premium associated with their high quality and safe products, subsequently encouraging producers to improve the quality of their products. Traditionally, millions of smallscale Chinese farmers supply food to the country, wherein most are brandless. However, with the enhanced degree of industrialization and organization, an increasing number of agricultural products in China have begun to be branded since the beginning of the $21^{\text {st }}$ century (Yue and Tong, 2011). The brand of agricultural products is to extend the function of the brand to the field of agricultural products. In the field of agricultural products, brand serves as a bridge between the operators of agricultural products and consumers. Labelling of agricultural products can increase consumers' discrimination of different agricultural products. These brands usually take one of the following two forms in China: the brand used by agricultural cooperatives and the brand used by proprietary agricultural enterprises (Yue and Tong, 2011). Cooperatives brand is an important type of agricultural product brand, it is the most important way for decentralized smallholder farmers to achieve branding in China. Compared with the 'public nature' of cooperatives brand, enterprise brand has its unique 'specificity', which is owned by a certain enterprise organization or individual, and has obvious competitiveness and exclusiveness. The advantage is that managers are more willing to take the initiative to contribute to brand building.

As agricultural certification labels and brands provide information about producers and products, consumers may use both to assess food safety. This study aims to evaluate whether consumer support exists for enhanced food safety in the produce market, as signaled by certification labels and brands, and to examine the interactions between these signals. We first conduct Becker-DeGroot-Marschak (BDM) auction experiments targeting Chinese consumers' preference for agricultural certification labels and brands. A menu selection experiment is subsequently performed to explore the interaction relationships between certification labels and brands. Furthermore, considering that many Chinese consumers' knowledge on certification is generally low (Liu et al., 2013), we examine the impact on consumers' willingness to pay (WTP) through their knowledge on certification.

The rest of this paper is organized as follows. Section 2 contains a literature review. Section 3 introduces experimental design. Section 4 presents the data source. Section 5 describes the econometric modeling. Section 6 includes a discussion of the results. Section 7 concludes the paper. 


\section{Literature review}

\subsection{Methods for eliciting consumers 'willingness to pay}

In recent years, experimental auctions and choice experiments have gradually gained popularity in studies that examined consumer WTP for food attributes. In the experimental auction theory, consumer bids for auction stimuli are close to their real values (Jack et al., 2009; Murphy et al., 2005). However, experimental auctions can only auction one specific product at a time; therefore, their application is cumbersome if the goal is to examine the interaction between different attributes (Jaeger et al., 2004), such as between certification labels and brands in this study.

The choice experiment is based on the random utility theory (Lancaster, 1966) and can simultaneously examine several attributes' WTP (Breidert et al., 2006). Under certain conditions, a choice experiment is also incentive-compatible (Breidert et al., 2006). However, a choice experiment can still result in hypothetical bias as it uses profiles composed of attributes and levels, which may lead consumers to choose one profile even if a higher utility is associated with another in a real situation (Ben-Akiva and Gershenfeld, 1998). Moreover, as consumers have to choose from preset product profiles with a total price, deviation in experimental results can occur because of consumer insensitivity to the price of virtual profiles (Hensher, 2010). Various modifications of choice experiments have been proposed in the literature to improve their efficacy. Among these, menu-based choice experiments allow consumers to choose product attributes independently (Liechty et al., 2001), and can also measure consumers' price sensitivity (Orme, 2010a). This type of experiment generates more virtual product profiles than those generated by the conventional choice experiments, thus effectively reducing non-compensatory substitution patterns between the attributes (Ben-Akiva and Gershenfeld, 1998) and lowering the response error due to consumer multitasking (Orme, 2010b).

\subsection{Consumer preference for food certification labels and brands}

Many studies have investigated consumer preference for food certification labels and brands (Basha and Lal, 2019; Dominici et al., 2020; Jessica et al., 2020; Liu, 2013; Liu et al., 2013; Meyerding et al., 2019; Truong et al., 2021; Watanabe et al., 2021). Janssen and Hamm (2012) investigated consumer WTP for different organic labels in six European countries and found that consumer WTP for different organic certification labels varied greatly. Chen et al. (2015) found that consumer WTP for tomatoes with the European Union organic label was remarkably higher than that for those with the Chinese organic label. Yin et al. (2017) found that consumers were willing to pay more for the organic label than for the green and hazard-free labels, with no difference in consumer WTP between the latter two. Zhang et al. (2018) conducted a survey of 840 consumers in China, and reported that $67.6 \%$ of consumers were willing to buy safe vegetables (includes hazard-free vegetables, green vegetables, and organic vegetables) and $65.8 \%$ would pay a premium price for safe vegetables. Yang et al. (2021) used the method of choice experiment to study consumers' preference for organic oolong tea, and the results showed that the origin, organic label and brand attribute were all important factors affecting the purchase of Oolong tea.

Brand is also an important attribute for consumers, according to many food studies (e.g. Ares et al., 2010; Carrillo et al., 2012). For most consumers, brand name is used as a 'search attribute' (Ahmad and Anders, 2012). Roheim et al. (2007) found that consumers were willing to pay more for popular brand name products, holding all other factors constant. Ares et al. (2010) found that consumers' WTP was positively affected by their brand preference. Lewis et al. (2016) examined consumer WTP for branded and unbranded energy drinks containing different sweeteners and showed that brand presence influenced the WTP for certain products. 


\subsection{Interaction relationship between food safety information attributes}

Some literatures have studied the relationship between the attributes of food quality information from the perspective of consumer preferences. Ubilava and Foster (2009) demonstrated a substitute relationship between government food safety and quality assurance and supply chain traceability. Ortega et al. (2011) revealed a substitute relationship between government safety inspection and third-party quality certification and between third-party quality certification and traceability, and showed a complementary relationship between government safety inspection and additional information labeling, between additional information labeling and traceability, and between government safety inspection and traceability. Lim et al. (2014) found a complementary relationship between safety assurance and traceability. Wu et al. (2016) reported a substitute relationship between traceability to slaughter and processing and local production, as well as a complementary relationship between traceability to slaughter and processing and nonlocal production.

Although substitute or complementary relationships between attributes have been determined, one-way or two-way interrelationships between attributes have not yet been investigated. Further, to the best of our knowledge, the relationship between food certification label and brand, and the relationship between different food certification labels have not been reported.

Based on the above analysis, the main contributions of this paper are as follows: First, combining the auction experiment with the menu choice experiment, in order to effectively integrate the advantages of non-hypothetical and hypothetical experimental methods and make up for their shortcomings, so as to make a beneficial exploration of consumer preference estimation methods. Second, based on the estimation of consumers' willingness to pay, the logit model is used to further investigate the interaction relationship between agricultural certification labels and brands. Third, according to whether the certification knowledge is introduced, the participants were divided into control group and treatment group to conduct a controlled experiment to analyze the effect of certification knowledge intervention on consumer preferences.

\section{Experimental design}

\subsection{Stimuli}

Tomatoes were chosen as the study object for two reasons. First, they are the most widely produced and consumed vegetable/fruit in mainland China. In 2019, the output of tomatoes in mainland China reached $62,764,671$ tonnes, accounting for $35 \%$ of the world total output. ${ }^{1}$ Second, Chinese tomato producers are small-sized, with dispersed production processes (Ma, 2017). Accordingly, brand association is comparatively rare for fresh tomatoes. Meanwhile, considering that no nationally known brand exists, the choice of tomatoes can help reduce the influence of already existing brands on consumer choices.

\subsection{Auction experimental design}

Based on the actual Chinese tomato market, five tomato attributes were used as stimuli in the experimental auctions. These variants included tomatoes with organic, green, and hazard-free labels as well as a proprietary agricultural enterprise brand (EnpBrand) and a specialized agricultural cooperative brand (CoopBrand). Instead of introducing a specific brand logo, we used plain text to express brand association to avoid bias associated with a particular name or logo of a brand.

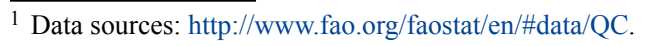




\section{- Auction mechanism choice}

To reduce strategic behavior and enhance sampling randomness, we applied the BDM mechanism in the experimental auction (Becker et al., 1964) and followed the standard procedure as follows. In a BDM auction, participants are asked to offer a bid for the considered product. The experimenter then extracts a price from a random number generator, which follows a certain distribution (bidders do not know the specific probability distribution). If a participant's bid is higher than the extracted price, the participant will win the product and pay the extracted price; otherwise, no transaction will occur (Becker et al., 1964). A trial round was then conducted to ensure that the participants were familiar with the procedure before the auction took place.

\section{- Auction preparation}

Before the start of the auction, we rewarded each participant with $500 \mathrm{~g}$ of conventional tomatoes (without certified labels or brands) purchased from local markets and further explained to each of them that the market price of local conventional tomatoes was approximately US\$ 0.61 per $500 \mathrm{~g}$. Meanwhile, a compensation of US\$ 2.28 (RMB ¥ 15) was provided to each participant. The experimenter then showed the participants five types of tomatoes that were up for auction (organic, green, hazard-free, EnpBrand, and CoopBrand). ${ }^{2}$ To eliminate the order effect (Orme, 2010b), we presented these five genres to the participants randomly. Furthermore, the participants were informed of the experimental rules, experimental process, and the questionnaire that followed the experiment. They were also informed that the tomatoes presented had different labels or brands but that no significant differences existed in other attributes, such as their appearance and size. No additional description was provided on experience and credence attributes, such as flavor, nutrients, and safety level.

\section{- Auction procedure}

Next, the participants were asked to successively bid on five types of tomatoes in five randomized rounds of the auction. In each round, a computer provided a random bid that satisfied the uniform distribution between the ranges of the largest and smallest bids provided by the participants. After the five rounds of the auction, using the dice method, a lottery system chooses one round from the five rounds as the final bidding round. Figure 1 shows the relevant experimental procedure.

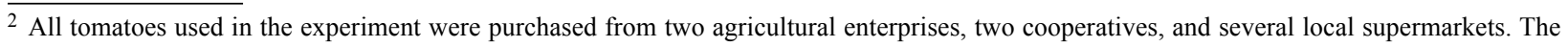
tomatoes had no clear or detectable differences in the appearance and color to the human eye.
}

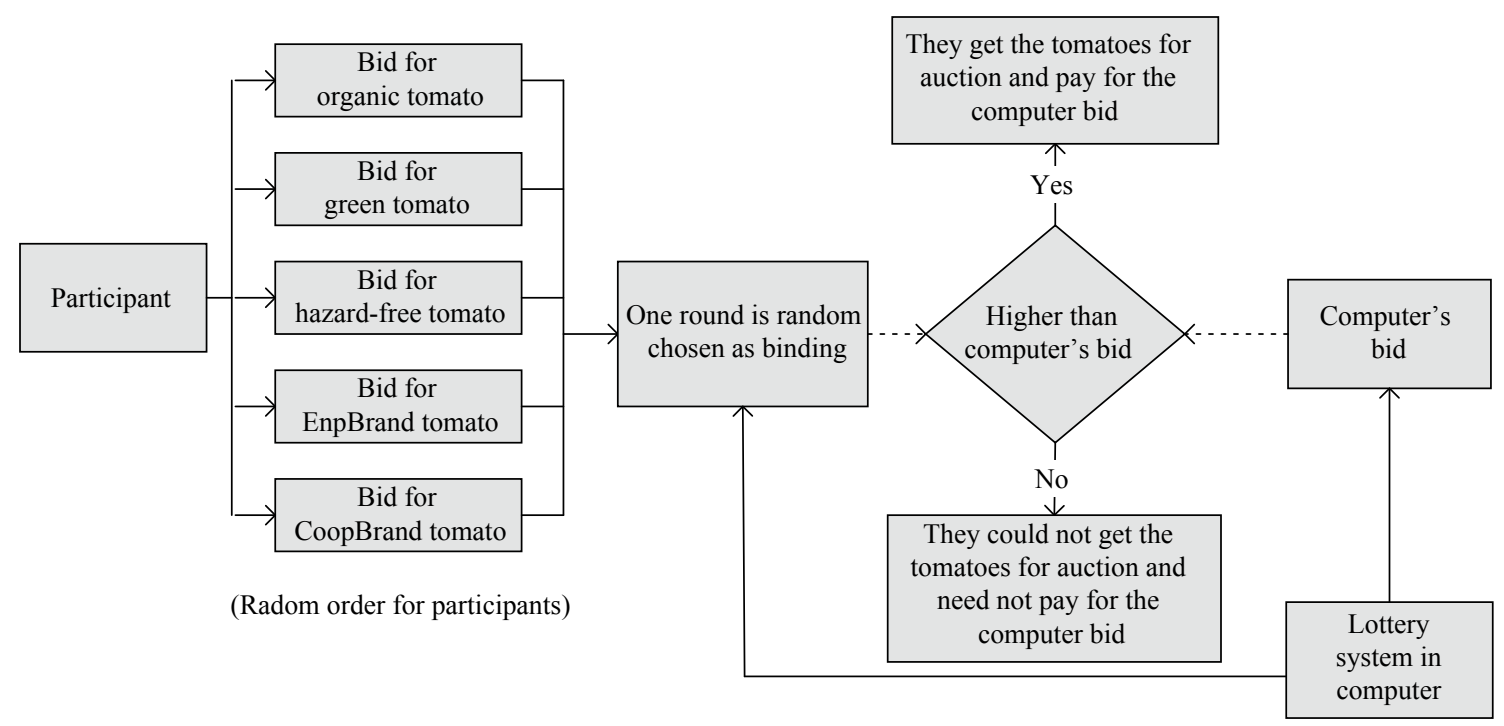

Figure 1. Becker-DeGroot-Marschak auction procedure. 


\section{- Information treatment}

To determine whether the lack of information on certification is the key factor that influences consumers' preference for certification labels, we followed Xie et al. (2016) and constructed two sets of BDM auction experiment. In the first set, no information was given to explain the certification labels. In the second set, the participants were given an introduction regarding the three certification labels. ${ }^{3}$ We refer to the respondent group receiving the information on certification as the 'treatment group' and that without this information as the 'control group'. Each participant was randomly assigned to one of the two groups. The participants in the control group already knew the certification labels. Therefore, differences between the two groups were considered the lower bound of the certification information effect.

\subsection{Menu-based choice experiment design}

Based on the results of the BDM auction experiment, we further explored the WTP data and used menubased choice experiments to assess the interaction relationships between food safety certification labels and brand attributes.

\section{- Menu-based choice experiment mechanism}

Figure 2 is an example of a menu-based choice experiment task card designed according to the price hierarchy of the reference group. There are three certification label attributes (i.e. organic, green, and hazard-free labels) and two brand attributes (i.e. EnpBrand and CoopBrand). Each product cannot simultaneously carry an enterprise and a cooperative label. Therefore, the participants were allowed to choose only one attribute between the two brand attributes and any number of the three certification labels they would like to have in

\footnotetext{
${ }^{3}$ The contents of this introduction were obtained from relevant official sources about organic/green/hazard-free food and related national standards in China. Five scholars were invited to comment on and edit the contents to ensure comprehension by the general public. Limited by space, we do not provide this material in the paper. In addition, we only introduced certification labels because the definitions of the two different types of brands were well known by Chinese consumers.
}

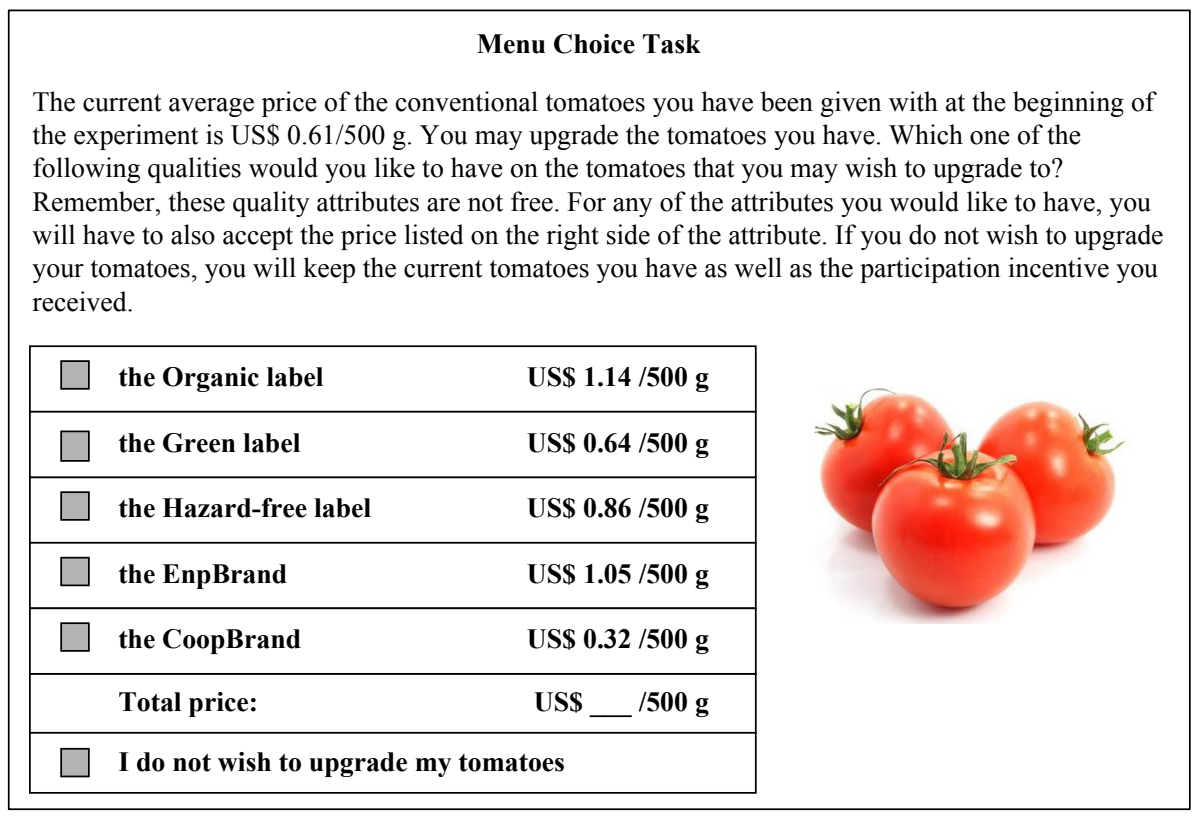

Figure 2. Sample of the menu-based choice experiment. 
the tomatoes with purchase intention. ${ }^{4}$ The total price of the product is then the sum of the base price, US\$ $0.61 / 500 \mathrm{~g}$, and any other attributes' prices that the participants have chosen. If they do not choose any of them, then this case shows that they only wish to keep the conventional tomatoes that they were given at the beginning of the experiment.

\section{- Menu-based choice experiment task design}

In the process of designing choice tasks, we followed the previous literature (e.g. Orme, 2013) and used five price levels for each tomato attribute. These five price levels were determined by first taking the mean bids that we obtained from the BDM experiment mentioned above as the median price and adjusting each by \pm 30 and $60 \%$ (Xie et al., 2016). In accordance, in BDM auction experiment, participants are divided into control group and treatment group according to whether the information interventions were implementd with, and the two groups of consumers should offer different bids, levels of attribute price were set differently in control group and treatment group (Table 1). Two sets of the menu choice experimental task were designed, to be completed by participants in control group and treatment group respectively.

Therefore, a total of $5 \times 5 \times 5 \times 5 \times 5=3,125$ combinations of attribute prices could be generated using the full factorial design. As a result, each participant would need to face 3,125 tasks, each task can produce $2^{5}=$ 32 product profiles for participants to choose. In general, distinguishing among 15-20 choice profiles may exhaust the participants (Allenby and Rossi, 1998; Wu et al., 2015). Therefore, selecting from 100,000 $(3,125 \times 32)$ choice profiles is unrealistic. Hence, the fractional factorial design was used to optimize the experimental scheme. Based on the study of Orme (2013), a questionnaire was constructed in this study

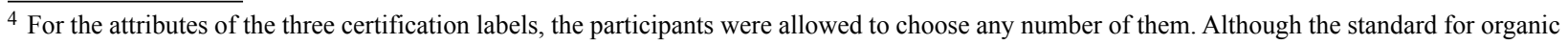
certification is stricter than for green or hazard-free certification, consumers may choose multiple labels out of irrational preference or out of the trust to a supplier having applied to multiple certification labels. Later in this paper, we will further discuss the substitutional or complementary relationship inside these certification labels.
}

Table 1. Setting of price levels for each information attribute (US\$/500 g).

\begin{tabular}{|c|c|c|c|c|c|c|c|}
\hline Attribute & Price level & $\begin{array}{l}\text { Control } \\
\text { group }\end{array}$ & $\begin{array}{l}\text { Treatment } \\
\text { group }\end{array}$ & Attribute & Price level & $\begin{array}{l}\text { Control } \\
\text { group }\end{array}$ & $\begin{array}{l}\text { Treatment } \\
\text { group }\end{array}$ \\
\hline \multirow[t]{6}{*}{ Organic } & \multicolumn{7}{|c|}{ Green } \\
\hline & I & 0.46 & 0.51 & & $\mathrm{I}$ & 0.37 & 0.45 \\
\hline & II & 0.80 & 0.90 & & II & 0.64 & 0.79 \\
\hline & III & 1.14 & 1.28 & & III & 0.92 & 1.13 \\
\hline & IV & 1.48 & 1.66 & & IV & 1.20 & 1.47 \\
\hline & $\mathrm{V}$ & 1.82 & 2.05 & & $\mathrm{~V}$ & 1.47 & 1.81 \\
\hline \multicolumn{4}{|c|}{ Hazard-free } & \multicolumn{4}{|l|}{ EnpBrand } \\
\hline & I & 0.26 & 0.28 & & I & 0.42 & 0.43 \\
\hline & II & 0.46 & 0.48 & & II & 0.74 & 0.75 \\
\hline & III & 0.66 & 0.69 & & III & 1.05 & 1.07 \\
\hline & IV & 0.86 & 0.90 & & IV & 1.37 & 1.39 \\
\hline & $\mathrm{V}$ & 1.06 & 1.10 & & V & 1.68 & 1.71 \\
\hline \multicolumn{8}{|l|}{ CoopBrand } \\
\hline & $\bar{I}$ & 0.32 & 0.33 & & & & \\
\hline & II & 0.56 & 0.57 & & & & \\
\hline & III & 0.80 & 0.82 & & & & \\
\hline & IV & 1.04 & 1.07 & & & & \\
\hline & $\mathrm{V}$ & 1.28 & 1.31 & & & & \\
\hline
\end{tabular}


with 10 versions $\times 10$ choice sets. The highest design efficiency was generated using Sawtooth MBC 1.0.10 (Sawtooth Software, Provo, UT, USA) via a balanced overlap randomized design.

\section{- Menu-based choice experiment processes}

The menu-based choice experiments were based on a paper-and-pencil survey (Wen et al., 2019). Each respondent was asked to evaluate 10 choice sets presented randomly. For each choice set, the participants were asked to choose their preferred attributes. After selections were made, the experimenter calculated the total amount of money for the participants and asked them to confirm whether they truly would like to upgrade their current tomatoes with those indicated through their choice under the total price needed; modifications were allowed.

Similarly to the BDM auction experiment, two sets of menu-based choice experiments were constructed. The participants were categorized into experimental and control groups based on whether information about the certification label attribute was provided. A compensation of US\$2.28 was given to each participant, which was similar to that in the BDM experiments.

\section{Data source}

The BDM auctions and menu-based choice experiments were conducted in Shandong Province, a populous province located in the Eastern coastal area of China. An imbalance of economic development could be observed from the east to the west of the province, which represents an imbalanced economic development throughout China. In our study, three cities were selected from each of the three regions (East: Qingdao, Weihai, and Rizhao; Central: Zibo, Tai'an, and Laiwu; West: Dezhou, Liaocheng, and Heze). Meanwhile, given the low demand for certified food in rural regions in China, this study is based only on urban consumers. Hence, a natural extension of the current study is to incorporate rural consumers.

Before the formal experiments, we conducted a preliminary survey in April 2017 in one of the nine cities to obtain the initial consumer perceptions on certified vegetables, purchasing channels, and preferences for vegetable brands, thus providing the basis for the experimental design of the BDM auction and menu-based choice experiment design. The results of this preliminary survey and relevant literature confirmed that the consumers of certified food lived mainly in cities and certified vegetables were mainly sold in supermarkets and farmers' markets located in the cities (Yin et al., 2019). Therefore, trained experiment assistants recruited study participants from supermarkets and farmer markets in the abovementioned cities (around half of them were recruited from supermarkets).

Before the formal experiment, 50 consumers from one of the nine cities were randomly selected to pre-test the BDM auction and menu-based choice experiment design. Formal BDM experiments were conducted between August and September 2017 in the abovementioned nine cities. A total of 476 consumers (around 50 in each city) agreed to participate in the survey, with an estimated response rate of $94.54 \%$. A total of 450 respondents completed the questionnaire (control group: 225; treatment group: 225). Formal menu-based choice experiments were conducted in the abovementioned cities between November and December 2017. A total of 896 consumers (around 100 in each city) agreed to participate in the survey, with an estimated response rate of $89.06 \%$. A total of 798 respondents completed the questionnaire (control group: 399; treatment group: 399). Table 2 lists the demographic characteristics of the two samples under both information treatments. 
Table 2. Sociodemographic characteristics of the respondents.

\begin{tabular}{|c|c|c|c|c|c|c|c|c|}
\hline \multirow{3}{*}{$\begin{array}{l}\text { Variables } \\
\text { Categories }\end{array}$} & \multicolumn{4}{|c|}{ Sample for BDM $^{1}$ auction } & \multicolumn{4}{|c|}{ Sample for menu-based choice } \\
\hline & \multicolumn{2}{|c|}{ Control group } & \multicolumn{2}{|c|}{ Treatment group } & \multicolumn{2}{|c|}{ Control group } & \multicolumn{2}{|c|}{ Treatment group } \\
\hline & $\begin{array}{l}\text { No. of } \\
\text { respondents }\end{array}$ & $\begin{array}{l}\text { \% of } \\
\text { sample }\end{array}$ & $\begin{array}{l}\text { No. of } \\
\text { respondents }\end{array}$ & $\begin{array}{l}\% \text { of } \\
\text { sample }\end{array}$ & $\begin{array}{l}\text { No. of } \\
\text { respondents }\end{array}$ & $\begin{array}{l}\text { \% of } \\
\text { sample }\end{array}$ & $\begin{array}{l}\text { No. of } \\
\text { respondents }\end{array}$ & $\begin{array}{l}\text { \% of } \\
\text { sample }\end{array}$ \\
\hline \multicolumn{9}{|l|}{ Gender } \\
\hline Male & 102 & 45.33 & 100 & 44.44 & 175 & 43.86 & 172 & 43.11 \\
\hline Female & 123 & 54.67 & 125 & 55.56 & 224 & 56.14 & 227 & 56.89 \\
\hline \multicolumn{9}{|l|}{ Age } \\
\hline$<40$ years old & 150 & 66.67 & 152 & 67.56 & 268 & 67.17 & 264 & 66.17 \\
\hline Else & 75 & 33.33 & 73 & 32.44 & 131 & 32.83 & 135 & 33.83 \\
\hline \multicolumn{9}{|l|}{ Education } \\
\hline University and above & 145 & 64.44 & 149 & 66.22 & 261 & 65.41 & 256 & 64.16 \\
\hline Else & 80 & 35.56 & 76 & 33.78 & 138 & 34.59 & 143 & 35.84 \\
\hline \multicolumn{9}{|c|}{ Family pretax income (annual) } \\
\hline$>$ US $\$ 15,228$ & 119 & 52.89 & 128 & 56.89 & 211 & 52.88 & 223 & 55.89 \\
\hline Else & 106 & 47.11 & 97 & 43.11 & 188 & 47.12 & 176 & 44.11 \\
\hline
\end{tabular}

\section{Econometric modeling}

The models associated with the BDM experiments follow a standard regression-type analysis; thus, we focused on the models to be used under the menu-based choice experiments. The theoretical basis of the menu-based choice experiments is the attribute utility theory of Lancaster (1966), who suggested that attributes rather than goods determine a consumer's utility. A binary logit model was used to study consumer preference toward food-safety certification labels and brands. Assuming that respondent $m$ selects the $j$-th tomato attribute from menu choice space $C$ under situation $t$, the potential utility $\left(U_{m j t}\right)$ can be expressed as follows:

$$
\begin{aligned}
& U_{m j t}=V_{m j t}+\varepsilon_{m j t} \\
& V_{m j t}=\alpha_{m j}+\beta_{m j} X_{m j t}
\end{aligned}
$$

where $V_{m j t}$ is the deterministic part of consumers' utility, $\varepsilon_{m j t}$ represents the random disturbances that are unobservable in consumers' utility, $\alpha_{m j}$ is a constant term, $X_{m j t}$ is the price vector of attributes, and $\beta_{m j}$ is the estimated parameter. Although the consumers' potential utility $\left(U_{m j t}\right)$ cannot be observed directly, it can be identified by their choices. Let $Y_{m j t}$ be an indicator variable showing whether a decision is made to choose tomato attribute $j$ :

$$
\left\{\begin{array}{lll}
Y_{m j t}=1 & \text { if } & U_{m j t}>0 \\
Y_{m j t}=0 & \text { if } & U_{m j t} \leq 0
\end{array}\right.
$$

If $U_{m j t}>0$, the consumer $m$ will choose the $j$ attribute in the $t$ situation, that is $Y_{m j t}=1$; On the contrary, if $U_{m j t} \leq 0$, the consumer $m$ will not choose the $j$ attribute in the $t$ scenario, that is $Y_{m j t}=0$. Therefore, the corresponding conditional probability of consumers choosing attribute $j$ can be written as:

$$
P\left(Y_{m j t}=1 \mid X_{m j t}\right)=P\left(\varepsilon_{m j t}^{>-\alpha_{m j}}-\beta_{m j} X_{m j t}\right)=F\left(-\alpha_{m j}-\beta_{m j} X_{m j t}\right)=1-F\left(\alpha_{m j}+\beta_{m j} X_{m j t}\right)
$$

If $\varepsilon_{m j t}$ satisfies Gumble's distribution, then Equation 4 transforms into

$$
P\left(Y_{m j t}=1 \mid X_{m j t}\right)=\frac{e^{\alpha_{m j}+\beta_{m j} X_{m j t}}}{1+e^{\alpha_{m j}}+\beta_{m j} X_{m j t}}
$$




\section{Results and discussion}

\subsection{Consumer WTP results of the BDM auction experiment}

Table 3 presents the raw distribution of consumer WTP under the BDM auction experiment, and Table 4 presents the $t$-test results of WTP for attributes under the two information treatments.

\section{- Consumer bids for tomatoes with different certification labels}

According to Tables 3 and 4, the results show significant differences in consumer bids toward the three certification labels. In the control group, the average consumer WTP toward the organic label is the highest at up to US\$1.14/500 g, followed by the green label (US\$ 0.92/500 g) and hazard-free label (US\$ 0.66/500 g), which are all higher compared to those of conventional tomatoes (US $\$ 0.61 / 500 \mathrm{~g}$ ). In the treatment group, the ranking follows a similar pattern, wherein organic labels are the highest (US\$ $1.28 / 500 \mathrm{~g}$ ), followed by the green label (US\$1.13/500 g) and hazard-free label (US\$ 0.69/500 g). However, based on the $t$-test result given in the last column in Table 3, compared to the control group, respondents in the treatment group have higher average WTP toward organic and green labels.

\section{- Consumers' bids for different brands of tomatoes}

Tables 3 and 4 indicate that, in both groups, consumers' bids for the enterprise brand are significantly higher than those for the cooperative brand. The last column of Table 3 suggests that no significant difference exists in the average WTP between the control group and treatment group, indicating that certification information provision has no significant influence on consumer WTP for brands.

\subsection{Model estimation results}

Sawtooth MBC 1.0.10 software was used to estimate Equation 5, and these results are reported in Table 5. The estimated results show that the pseudo $R^{2}$ of each model is greater than 0.6 , indicating that the overall

Table 3. Consumer $\mathrm{WTP}^{1}$ for different attributes based on the $\mathrm{BDM}^{1}$ auction (US\$/500 g). ${ }^{2}$

\begin{tabular}{|c|c|c|c|c|c|c|c|}
\hline \multirow[t]{2}{*}{ Attribute } & \multicolumn{3}{|c|}{ Control group } & \multicolumn{3}{|c|}{ Treatment group } & \multirow[t]{2}{*}{$\Delta$ Mean } \\
\hline & Max. & Min. & Mean & Max. & Min. & Mean & \\
\hline Organic & 2.16 & 0.0 & 1.14 & 2.46 & 0.0 & 1.28 & $0.14 * * *$ \\
\hline Green & 1.69 & 0.0 & 0.92 & 2.00 & 0.0 & 1.13 & $0.21 * * *$ \\
\hline Hazard-free & 1.09 & 0.0 & 0.66 & 1.04 & 0.0 & 0.69 & $0.03 * *$ \\
\hline EnpBrand & 2.00 & 0.0 & 1.05 & 1.87 & 0.0 & 1.07 & 0.02 \\
\hline CoopBrand & 1.23 & 0.0 & 0.80 & 1.29 & 0.0 & 0.82 & 0.02 \\
\hline
\end{tabular}

${ }^{1}$ BDM $=$ Becker-DeGroot-Marschak; WTP $=$ willingness to pay.

$2 * *$ and $* * *$ denote significance at the 5 and $1 \%$ levels, respectively.

Table 4. $t$-test for mean willingness to pay for attributes under different information treatments. ${ }^{1}$

\begin{tabular}{|c|c|c|c|c|c|c|c|c|}
\hline \multirow[t]{2}{*}{ Attribute } & \multicolumn{4}{|c|}{ Control group } & \multicolumn{4}{|c|}{ Treatment group } \\
\hline & Organic & Green & Hazard-free & EnpBrand & Organic & Green & Hazard-free & EnpBrand \\
\hline Green & $-1.31 * *$ & - & - & - & $-1.57 * *$ & - & - & - \\
\hline Hazard-free & $-1.93 * *$ & $-2.03 * *$ & - & - & $-2.17 * *$ & $-2.39 * * *$ & - & - \\
\hline EnpBrand & $-1.81 * *$ & $-2.29 * *$ & $1.01 * *$ & - & $-1.85^{*}$ & $2.91 *$ & $1.72 * *$ & - \\
\hline CoopBrand & $-1.85^{* *}$ & $-2.43 *$ & $0.82 * *$ & $-1.72 * *$ & $-1.91 * *$ & $-2.52 * * *$ & $1.37 *$ & $-1.76^{* *}$ \\
\hline
\end{tabular}

$1 *, * *$ and $* * *$ denote significance at the 10,5 and $1 \%$ levels, respectively. Figures in the table are $t$-values of differences between the row and column attributes' mean willingness to pay values. 
fitting effect is good. A significant negative relationship exists between the price of each attribute and the probability of the attribute being chosen, which is consistent with the conclusions of descriptive analyses and simple statistical tests. To better illustrate this interaction, Figure 3 is presented on the basis of the data reported in Table 5.

Table 5. Logit model estimation results. ${ }^{1}$

\begin{tabular}{|c|c|c|c|c|}
\hline \multirow{2}{*}{$\begin{array}{l}\text { Dependent variable } \\
\text { Independent variable }\end{array}$} & \multicolumn{2}{|c|}{ Control group } & \multicolumn{2}{|c|}{ Treatment group } \\
\hline & Coefficient & $t$-value & Coefficient & $t$-value \\
\hline \multicolumn{5}{|l|}{ Model 1: Organic } \\
\hline Price of organic & $-0.768^{* *}$ & 0.0434 & $-0.534^{* * *}$ & 0.0067 \\
\hline Price of green & $1.234^{* *}$ & 0.0342 & $1.564^{* *}$ & 0.0231 \\
\hline Prize of hazard-free & $1.034^{*}$ & 0.0852 & $1.274^{* *}$ & 0.0462 \\
\hline Prize of EnpBrand & $-2.422^{*}$ & 0.0965 & $-3.865^{*}$ & 0.0752 \\
\hline Price of CoopBrand & $-3.231^{*}$ & 0.0642 & $-4.532^{*}$ & 0.0734 \\
\hline ASC & $-2.346^{* * *}$ & 0.0003 & $-3.234^{* * *}$ & 0.0006 \\
\hline $\mathrm{R}^{2}$ & 0.7826 & & 0.8143 & \\
\hline \multicolumn{5}{|l|}{ Model 2: Green } \\
\hline Price of organic & $0.568^{* *}$ & 0.0234 & $0.756^{* *}$ & 0.0287 \\
\hline Price of green & $-1.037^{* *}$ & 0.0342 & $-0.576^{* * *}$ & 0.0098 \\
\hline Prize of hazard-free & $0.024^{*}$ & 0.0752 & $0.195^{*}$ & 0.0765 \\
\hline Prize of EnpBrand & $-0.068^{* *}$ & 0.0435 & $-1.103^{* *}$ & 0.0213 \\
\hline Price of CoopBrand & $-0.107^{* * *}$ & 0.0000 & $-1.391^{* *}$ & 0.0317 \\
\hline ASC & $-5.323^{* * *}$ & 0.0021 & $-4.423^{* * *}$ & 0.0030 \\
\hline $\mathrm{R}^{2}$ & 0.7762 & & 0.8598 & \\
\hline \multicolumn{5}{|l|}{ Model 3: Hazard-free } \\
\hline Price of organic & $1.324^{* *}$ & 0.0437 & 0.239 & 0.1128 \\
\hline Price of green & $0.934^{* * *}$ & 0.0076 & 0.897 & 0.2087 \\
\hline Prize of hazard-free & $-3.432^{* * *}$ & 0.0034 & $-2.897^{* * *}$ & 0.0065 \\
\hline Prize of EnpBrand & 1.243 & 0.1972 & $2.234^{*}$ & 0.0931 \\
\hline Price of CoopBrand & 0.483 & 0.1843 & $0.543^{*}$ & 0.0642 \\
\hline ASC & $-6.232^{* * *}$ & 0.0001 & $-3.241^{* * *}$ & 0.0025 \\
\hline $\mathrm{R}^{2}$ & 0.8065 & & 0.8285 & \\
\hline \multicolumn{5}{|l|}{ Model 4: EnpBrand } \\
\hline Price of organic & $1.268^{* *}$ & 0.0324 & $1.941^{* * *}$ & 0.0021 \\
\hline Price of green & $1.386^{* * *}$ & 0.0008 & $2.236^{*}$ & 0.0593 \\
\hline Prize of hazard-free & $1.831^{*}$ & 0.0964 & $2.974^{*}$ & 0.0923 \\
\hline Prize of EnpBrand & $-0.442^{* * *}$ & 0.0002 & $-1.831^{*}$ & 0.0674 \\
\hline Price of CoopBrand & $4.611^{*}$ & 0.0643 & $3.324^{*}$ & 0.0648 \\
\hline ASC & $-2.346^{* * *}$ & 0.0000 & $-3.234^{* * *}$ & 0.0001 \\
\hline $\mathrm{R}^{2}$ & 0.6742 & & 0.7264 & \\
\hline \multicolumn{5}{|l|}{ Model 5: CoopBrand } \\
\hline Price of organic & $1.462^{* * *}$ & 0.0005 & $1.247^{* *}$ & 0.0172 \\
\hline Price of green & $1.654^{* *}$ & 0.0214 & $1.576^{* * *}$ & 0.0001 \\
\hline Prize of hazard-free & $1.834^{*}$ & 0.0923 & $2.145^{*}$ & 0.0865 \\
\hline Prize of EnpBrand & $0.047^{*}$ & 0.0842 & $1.643^{* *}$ & 0.0243 \\
\hline Price of CoopBrand & $-0.246^{* * *}$ & 0.0006 & $-1.353^{* *}$ & 0.0421 \\
\hline ASC & $-5.244^{* * *}$ & 0.0000 & $-4.453^{* * *}$ & 0.0008 \\
\hline $\mathrm{R}^{2}$ & 0.6234 & & 0.7653 & \\
\hline
\end{tabular}

$1 *, * *$ and $* * *$ denote significance at the 10,5 and $1 \%$ levels, respectively. 


\section{- Interaction relationships among certification labels}

The results shown in Table 5 and Figure 3 indicate that two of the three certification labels have different interaction relationships.

First, Table 5 shows that the coefficient of the Price of green variable in Model 1 and the coefficient of the Price of organic variable in Model 2 are both significantly positive for both groups. This result, for example, shows that consumers will prefer to choose the organic label when the price associated with the green label is higher and the green label when the price of the organic label increases. The organic and green labels were found to be substitutes. The reason for this may be that the participants believe that green and organic are healthy and harmless to the body. This is consistent with the results in Table 3 that the participants' willingness to pay for organic food and green food is similar. This shows that although there are many producers apply for organic certification and green certification at the same time, from the perspective of consumer preferences, it is of little value to apply for these two certifications simultaneously.
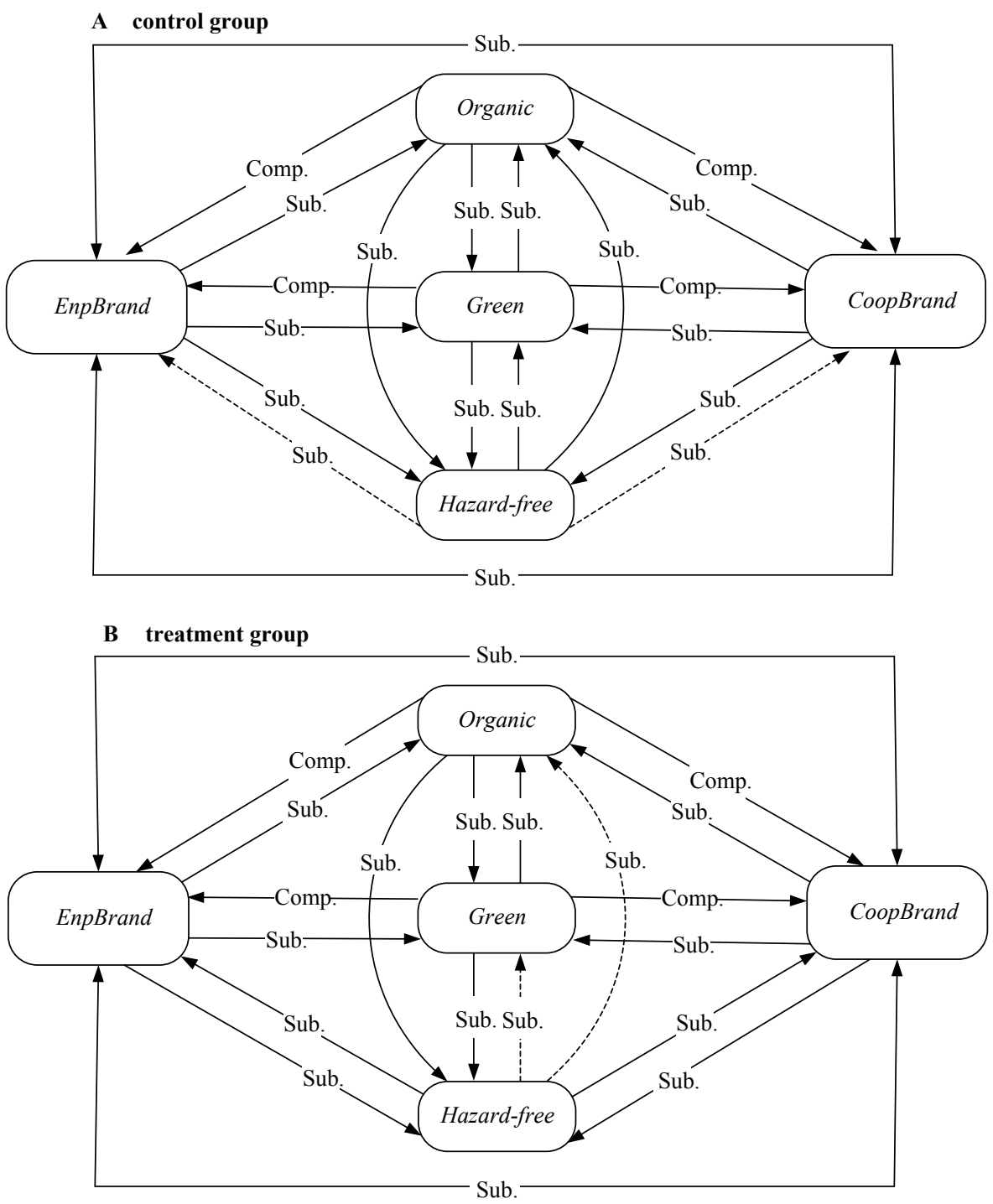

Figure 3. Relationships among safety certification labels and brands. Solid lines represent relationships between two attributes at the significant level of 10, 5 or 1\%. Dashed lines denote insignificant relationships. Sub. $=$ substitutional; Comp. $=$ complementary. 
Second, the interaction relationships between the hazard-free and organic labels and those between the hazard-free and green labels are all significantly two-way substitutional in the control group, whereas the relationship is one-way substitutional in the treatment group. The estimation results of Models 1 and 2 show that the coefficients of the Prize of hazard-free variables are significantly positive. When the price of the hazard-free label increases, respondents from both groups would prefer to choose the organic or green label to replace the hazard-free label. The estimation results in Model 3 show that the coefficient of the Price of organic variable and that of the Price of green variable are both significantly positive in the control group. When the prices of organic or green labels increase, control group consumers would use the hazard-free label to replace organic or green labels. In the treatment group, the coefficients of the two above variables are positive but not significantly, indicating that consumers will not replace organic or green labels with hazard-free labels when the prices of organic or green labels increase. Respondents of the treatment group gain more information regarding certification and will more likely have a clearer understanding of the differences between the three types of certification labels, especially the knowledge that organic and green foods are more secure than hazard-free food. The ratchet effect ${ }^{5}$ explains why consumers are not willing to lower their standards of consumption to hazard-free tomatoes, which are relatively cheap, after they have already consumed organic or green food before.

\section{- Interaction relationships among brand labels}

The results in Table 5 show that there is a significant two-way substitution relationship between the two brands of agricultural products. From the results of model 4, both in the control and treatment group, the coefficients of the Price of CoopBrand variables are significantly positive; from the results of model 5, the coefficients of the Prize of EnpBrand are significantly positive. This shows that there is a significant two-way substitution between the two brand labels. This result shows that with the increase of CoopBrand label prices, consumers will tend to choose EnpBrand labels instead of CoopBrand labels. When the price of EnpBrand label increases, consumers will prefer to choose the CoopBrand labels and reduce the choice of EnpBrand labels.

The substitution relationship between the two brands may be caused by the different forms of agricultural operation of the two brands. The EnpBrand is mainly based on agricultural products processing enterprises, which is owned by an enterprise organization or individual alone, and has 'specificity'. Other enterprises cannot share the benefits brought by the enterprise brand, which is obviously competitive and exclusive, Therefore, EnpBrand owners take various measures to promote consumers' purchase for greater interests. Compared with EnpBrand, CoopBrand promote consumers' purchase through decentralized farmers' unified brand management, production standardization and intensification, unified management of interest coordination mechanism, and joint promotion of brand promotion in the brand building of agricultural products. Therefore, both EnpBrand and CoopBrand have their own ways to promote consumers' purchase.

\section{- Interaction relationships of certification labels and brands}

Data in Table 5 shows that the regression results of interaction relationships between 3 certification labels and EnpBrand are only slightly different from those of their interaction with CoopBrand in terms of coefficient sign and its significance. Therefore, we focus on the interaction relationships between the certification labels and EnpBrand.

The estimated results of Models 1 and 2 show that consumers in the control and treatment groups have similar selection results. The results indicate that the coefficients the Prize of EnpBrand variables are significantly negative. Compared to the control group, both absolute values of coefficients are higher in the treatment group, indicating that the participants are less likely to choose organic or green labels when the EnpBrand

\footnotetext{
${ }^{5}$ The ratchet effect refers to the irreversibility of the consumers' consumption habit after it is formed; that is, the consumption habit is easy to adjust upward, but difficult to adjust downward.
} 
price increases. This may be because producers with the organic or green certification also own brands in China. Almost no brandless organic or green foods are available on the market, and consumers in the treatment group will be more aware of this situation. Therefore, few consumers are likely to buy brandless organic or green foods. Therefore, when the price of a brand increases, consumers will reduce their consumption of branded products; accordingly, the consumption of organic or green foods declines. The estimation results of Model 3 show that the coefficient of the Prize of EnpBrand variable is positive but not significant in the control group, whereas significantly positive in the treatment group. These results indicate that the hazard-free label can be used as a substitute for EnpBrand in the treatment group. When the EnpBrand price increases, consumers in the treatment group will prefer to choose hazard-free certified tomatoes.

The estimation results of Model 4 show that the coefficients of the Price of organic, Price of green and Prize of hazard-free variables are all significantly positive and that the consumer choice results are similar between the control and treatment groups. When the prices of organic, green, or hazard-free labels increase, the participants are more likely to replace certification labels with EnpBrand. These two kinds of attributes show a significant substitutional relationship, which is consistent with that between the food safety labels and brands determined by Yin et al. (2017).

The results in Table 5 show that there is no significant difference between CoopBrand and EnpBrand regarding the relationship between them and certification labels. Since organic and green labels cannot substitute CoopBrand, scattered smallholder farmers should also establish corresponding brands when carrying out organic certification or green certification through cooperatives.

\section{Conclusions and implications}

In this study, two attribute genres of food quality assurance - certification labels (organic, green, and hazardfree labels) and brands (enterprise and agricultural cooperative brands) - were established for tomatoes. Consumer preferences for, and interaction relationships among, the quality attributes of tomatoes were investigated using BDM auctions and menu-based choice experiments. The following major conclusions and implications can be drawn from this research.

\subsection{Conclusions}

First, consumers are generally willing to pay a higher price for certified tomatoes, especially organic tomatoes, than for conventional tomatoes. The provision of information on certification can significantly improve consumer WTP for organic and green tomatoes, but has little influence on WTP for hazard-free tomatoes. Consumers are generally willing to pay higher prices for branded tomatoes and the WTP of proprietary agricultural enterprise brands is higher than that of cooperative brands.

Second, a two-way alternative relationship exists between the green and organic labels. Significant two-way substitutional relationships are observed in the relationships between hazard-free and organic labels and between hazard-free and green labels in the control group, whereas a one-way substitutional relationship is observed under those of the treatment group.

Third, the organic label (green label) cannot replace the enterprise brand, which has a substitutional relationship on the organic label (green label). A two-way substitutional relationship exists between the hazard-free label and enterprise brand, which is more significant in the treatment group.

\subsection{Implications}

First, a certification label and brand can significantly improve consumer WTP. Therefore, the choice of certification production or implementation of brand strategy is conducive to the improvement in market demand for suppliers. For the Chinese agricultural sector, which is dominated by decentralized small-scale 
farmers' production, the positive influence of expanding market demand is expected to promote brand upgrades and participation in various certification production practices using strategies of 'enterprises + farmers' and cooperatives.

Second, the popularization of certification knowledge is expected to promote the development of the certified food market. Considering the existence of public goods and positive externalities in the safety and ecological attributes of certified food, disseminating information on certified food should become the common responsibility of manufacturers, governments, and other social parties.

Third, producers seeking certification and branding strategies should thoroughly consider the interaction relationships between certification labels and brands. The consumers' perceived value of adding multiple certification labels to the same product is unclear because of the remarkable substitutional relationships between any pair of the three labels. In particular, organic labels (green labels) may easily replace hazardfree labels with the improvement in consumer certification knowledge. Organic (green) food producers must, therefore, implement aggressive branding strategies to enhance consumer preference.

\section{Acknowledgements}

This paper was supported by the study on the Modernization of Social Governance System and Capacity in the Field of Food Safety, a project funded by the National Social Science Fund of China (Grant No. 20BJY016), the Science and Technology Support Plan for Outstanding Young Innovation Team in Shandong Province, China (Grant No. 2019RWG009), the Social Science Fund of Shandong Province, China (Grant No. 19BJC11), and the Philosophy and Social Science Planning Project in Shandong Province, China (Grant No. 19CGLJ04).

\section{Conflict of interest}

The authors declare no conflict of interest.

\section{References}

Ahmad, W. and S. Anders. 2012. The value of brand and convenience at tributes in highly processed food products. Canadian Journal of Agricultural Economics 60(1): 113-133.

Allenby, G.M. and P.E. Rossi. 1998. Marketing models of consumer heterogeneity. Journal of Econometrics 89(1): 57-78.

Ares, G., A. Gimenez and R. Deliza. 2010. Influence of three non-sensory factors on consumer choice of functional yogurts over regular ones. Food Quality and Preference 21(4): 361-367.

Basha, M.B. and D. Lal. 2019. Indian consumers' attitudes towards purchasing organically produced foods: an empirical study. Journal of Cleaner Production 215: 99-111.

Becker, G.M., M.H. DeGroot and J. Marschak. 1964. Measuring utility by a single-response sequential method. Behavioral Science 9(3): 226-232.

Ben-Akiva, M. and S. Gershenfeld. 1998. Multi-featured products and services: analysing pricing and bundling strategies. Journal of Forecasting 17(3): 175-196.

Breidert, C., M. Hahsler and T. Reutterer. 2006. A review of methods for measuring willingness-to-pay. Innovative Marketing 4(2): 8-32.

Carrillo, E., P. Varela and S. Fiszman. 2012. Packaging information as a modulator of consumers' perception of enriched and reduced-calorie biscuits in tasting and non-tasting tests. Food Quality and Preference 25(2): 105-115.

Chen, M., S.J. Yin and Z.W. Wang. 2015. Consumers' willingness to pay for tomatoes carrying different organic certification labels: evidence from auction experiments. British Food Journal 117(11): 2814-2830.

Chen, M., Y.Q. Wang and S.J. Yin. 2019. Research on the reformation path of China's food safety certification policy: from the perspective of consumer preference. Economy and Management Press, Beijing, China. 
Dominici, A., F. Boncinelli, F. Gerini and E. Marone. 2020. Consumer preference for wine from handharvested grapes. British Food Journal 122(8): 2551-2567.

Hensher, D.A. 2010. Hypothetical bias, choice experiments and willingness to pay. Transportation Research Part B Methodological 44(6): 735-752.

Jack, B.K., B. Leimona and P.J. Ferraro. 2009. A revealed preference approach to estimating supply curves for ecosystem services: use of auctions to set payments for soil erosion control in Indonesia. Conservation Biology 23(2): 359-367.

Jaeger, S.R., J.L. Lusk, L.O. House, C. Valli, M. Moore, B. Morrow and W.B. Traill. 2004. The use of nonhypothetical experimental markets for measuring the acceptance of genetically modified foods. Food Quality and Preference 15(7): 701-714.

Janssen, M. and U. Hamm. 2012. Product labelling in the market for organic food: consumer preferences and willingness-to-pay for different organic certification logos. Food Quality and Preference 25(1): 9-22.

Jessica, A., H. Spencer and C. Ying. 2020. Are low-income consumers willing to pay for fortification of a commercially produced yogurt in Bangladesh. Food and Nutrition Bulletin 41(1): 102-120.

Lancaster, K.J. 1966. A new approach to consumer theory. Journal of Political Economy 74(2): 132-157.

Lewis, K.E., C. Grebitus and R.M. Nayga Jr. 2016. The impact of brand and attention on consumers' willingness to pay: evidence from an eye tracking experiment. Canadian Journal of Agricultural Economics 64(4): 753-777.

Liao, C.H., X.M. Zhou and D.T. Zhao. 2018. An augmented risk information seeking model: perceived food safety risk related to food recalls. International Journal of Environmental Research and Public Health 15(9): 1800.

Liechty, J., V. Ramaswamy and S.H. Cohen. 2001. Choice menus for mass customization: an experimental approach for analyzing customer demand with an application to a web-based information service. Journal of Marketing Research 38(2): 183-196.

Lim, K.H., W.Y. Hu, L.J. Maynard and E. Goddard. 2014. A taste for safer beef? How much does consumers' perceived risk influence willingness to pay for country-of-origin labeled beef. Agribusiness 30(1): 17-30.

Liu, J.X. 2013. Current predicament and development direction of professional farmer cooperatives in China - '2012 international year of cooperatives: international trend of agricultural cooperatives and Chinese practice' international symposium review. Chinese Rural Economy 3: 89-96.

Liu, R., Z. Pieniak and W. Verbeke. 2013. Consumers' attitudes and behaviour towards safe food in China: a review. Food Control 33(1): 93-104.

Ma, Z.H. 2017. The trend of tomato varieties in China: the study of supply and demand. China Vegetable 3: $1-5$.

Meyerding, S.G.H., N. Trajer and M. Lehberger. 2019. What is local food? The case of consumer preferences for local food labeling of tomatoes in Germany. Journal of Cleaner Production 207: 30-43.

Murphy, J.J., P.G. Allen, T.H. Stevens and D. Weatherhead. 2005. A meta-analysis of hypothetical bias in stated preference valuation. Environmental and Resource Economics 30(3): 313-325.

Orme, B.K. 2010a. Menu-based choice modeling using traditional tools. Sawtooth Software Conference Proceedings, Sequim, WA, USA.

Orme, B.K. 2010b. Task order effects in menu-based choice. Sawtooth Software, Sequim, WA, USA.

Orme, U.T. 2013. Software for menu-based choice analysis. Sawtooth Software, Sequim, WA.

Ortega, D.L., H.H. Wang, L. Wu and N.J. Olynk. 2011. Modeling heterogeneity in consumer preferences for select food safety attributes in China. Food Policy 36(2): 318-324.

Roheim, C.A., L. Gardiner and F. Asche. 2007. Value of brands and other attributes: hedonic analysis of retail frozen fish in the UK. Marine Resource Econonic 22(3): 239-253.

Truong, V.A., D.M. Conroy and B. Lang. 2021. The trust paradox in food labelling: an exploration of consumers' perceptions of certified vegetables. Food Quality and Preference 93(9-10): 104280.

Ubilava, D. and K. Foster. 2009. Quality certification vs. product traceability: consumer preferences for informational attributes of pork in Georgia. Food Policy 34(3): 305-310. 
Watanabe, E., S. Alfinito and L.L. Barbirato. 2021. Certification label and fresh organic produce category in an emerging country: an experimental study on consumer trust and purchase intention. British Food Journal 123(6): 2258-2271.

Wen, X.W., S.L. Sun, L. Li and Q.Y. He. 2019. Avian influenza-factors affecting consumers' purchase intentions toward poultry products. International Journal of Environmental Research and Public Health 16(21): 4139.

Wu, L.H., H.S. Wang, D. Zhu, W.Y. Hu and S.X. Wang. 2016. Chinese consumers' willingness to pay for pork traceability information-the case of Wuxi. Agricultural Economics 47(1): 71-79.

Wu, L.H., S.X. Wang, D. Zhu, W.Y. Hu and H.S. Wang. 2015. Chinese consumers' preferences and willingness to pay for traceable food quality and safety attributes: the case of pork. China Econmic Review 35: 121-136.

Xie, J., Z. Gao, M. Swisher and X. Zhao. 2016. Consumers' preferences for fresh broccolis: interactive effects between country of origin and organic labels. Agricultural Economics 47(2): 181-191.

Yang, X., Q. Chen, N. Lin, M. Han and Z. Xu. 2021. Chinese consumer preferences for organic labels on Oolong tea: evidence from a choice experiment. International Food and Agribusiness Management Review 24(3): 545-561.

Yin, S.J., M. Chen, Y.J. Xu and Y.S. Chen. 2017. Chinese consumers' willingness-to-pay for safety label on tomato: evidence from choice experiments. China Agricultural Economic Review 9(1): 141-155.

Yin, S.J., R. Li and L.H. Wu. 2018. Introduction to 2018 China development report on food safety. Peking University Press, Beijing, China.

Yin, S.J., Y.Q. Wang and K. Li. 2019. Pre-certification or retrospective: the study of consumer preferences for food safety information labels and their interactive relationships. China Rural Survey 5: 127-144.

Yue, C. and C. Tong. 2011. Consumer preferences and willingness to pay for existing and new apple varieties: Evidence from apple tasting choice experiments. HortTechnology 21(3): 376-383.

Zhang, B., Z.T. Fu, J. Huang, J.Q. Wang, S.Y. Xu and L.X. Zhang. 2018. Consumers' perceptions, purchase intention, and willingness to pay a premium price for safe vegetables: a case study of Beijing, China. Journal of Cleaner Production 197(1): 1498-1507. 
